Vietnam Academy of Science and Technology
Vietnam Journal of Earth Sciences
http://www.vjs.ac.vn/index.php/jse

\title{
Utilization of seismic refraction data for the study of structure of Bang hot-water source, Le Thuy, Quang Binh
}

\author{
Tran Anh Vu*1,2, Dinh Van Toan1, Doan Van Tuyen¹, Lai Hop Phong'1, Duong Thi Ninh¹, \\ Nguyen Thi Hong Quang', Pham Ngoc Dat ${ }^{1}$ \\ ${ }^{1}$ Institute of Geological Sciences, Vietnam Academy of Science and Technology \\ ${ }^{2}$ Graduate University of Science and Technology, Vietnam Academy of Science and Technology \\ Received 01 June 2016. Accepted 10 December 2016
}

\begin{abstract}
Study of the geological structural elements in the area of geothermal sources is important for identifying the geothermal reservoir, the object is capable of energy production. This paper presents the preliminary results of the structural study obtained by the seismic refraction data in the area of hot water spring Bang, Le Thuy, Quang Binh. The exploration was carried out in 2014 by using 150 wireless Texan instruments produced by Refraction Technology Company - USA and provided by the Institute of Earth Sciences, Academia Sinica, Taiwan. The data were collected from 4 profiles, cutting several tectonic faults around the exposed hot water source. The seismic signals were strong on the records of each instrument, especially the signals of refraction wave. The 2D seismic tomographic technique is applied for data interpretation to create the velocity structural models from 4 observation profiles. Based on the velocity structures, the area can be separated into three main structural layers, characterized generally by three velocity ranges: $3,0-4,1 \mathrm{~km} / \mathrm{s} ; 4,2-5,1 \mathrm{~km} / \mathrm{s}$ and $5,2-6,1 \mathrm{~km} / \mathrm{s}$, respectively.

The block separation by the faults of different size with the subsidence tendency from southwest to the northeast parts of the region is apparently reflected in the seismic data obtained in this study. The narrow lower velocity vertical structure detected inside the southern well-consolidated rock uplifted block away from the exposed hot water source more than $2 \mathrm{~km}$, under the sub meridian extension Quaternary structure probably related to the breaking up of the bedrocks caused by the tectonic activity in the region. Perhaps, the object played a role as the thermal fluid channel in the geological history time and is closely related to the geothermal reservoir predicted recently by magnetotelluric investigations in this location.
\end{abstract}

Keywords: seismic refraction, 2D modeling, structure, geothermal Source Bang.

(C)2016 Vietnam Academy of Science and Technology

\section{Introduction}

Up to now the geothermal energy used in the World occupies a small portion in

${ }^{*}$ Corresponding author, Email: anhvu3110@yahoo.com comparison with the other types. Since geothermal energy is the renewable sources, much less affected to the environmental pollution, it became the object of interest to develop in many countries. The geothermal 
Tran Anh Vu, et al./Vietnam Journal of Earth Sciences 38 (2016)

systems characterized by reservoir structure capable of temperature storage and restoration of the geothermal regime can be used for generation of electric energy. For this reason, the identification of geothermal reservoir and it's related parameters such as it's distribution and dimension is important (Honjas et. Al., 1997; Uruh, 2001 ). Up to now most of the detected reservoirs is located at the depth of less than $1 \mathrm{~km}$ from the surface ( Doan Van Tuyen, et al. 2008), so the deep structures must be investigated. Just several geophysical methods, such as magnetotelluric and seismic investigations can be used effectively for solving this problem. The magnetotelluric measurements are often applied for searching both the reservoir structure and the source of heat supply, so the depth needs to be investigated in general is more than $10 \mathrm{~km}$. The seismic exploration with the use of active source is mainly applied to study the structures of the expected reservoir itself, which is mostly revealed at a depth range 1 - $4 \mathrm{~km}$. Though more detail structural feature of the study area can be obtained by applying the seismic reflection method, but a complexity of the local condition (strong topographical separation, scattered population points), limited budget and requirement of a dense network of shot points do not allow us to realize the operation of this method. Since the seismic investigations in this study aimed to provide more information regarding the structures and tectonic faults for fortified confidence of reservoir existence prediction fulfilled by using the magnetotelluric data, so the refraction method using wireless Texan instruments chosen for the exploration is satisfied the requirements and easier to realize. In a layered media when the seismic wave ray strikes an interface marking the change of seismic impedance $\mathrm{V} \rho$ ( product of density and velocity), the energy of the wave is partitioned to initiate the derivative rays as a reflected coming back to the surface and transmission entering into the deeper layer. If the velocity in the underlying is greater than the overlying ones at a certain distance from the source, a transmission ray will appear and create an angle of near $90^{\circ}$ with the normal line of the interface, the horizontally travel of the ray is being happened immediately below the interface. The coming back to the surface derivative wave generated by the interaction of horizontal movement of the primary ray with overlying environment is called the refraction wave. In such a way of wave generation the refraction wave can be recorded from a certain distance from the source (Lay W., 1995; Mai Thanh Tan, 2011). Since the travel velocity along the interface is greater than in the overlying layer, the refraction ray is arrived more early at the observation points, so it often called a head wave. If useful signals are strong enough, the determination of travel time can be performed with high precision. It is the basic way to get a more reliable velocity structural model under observation profiles. If the velocity of each layer in the horizontal layered media is assumed to be a constant, the travel time is described by a straight segment with the slope to horizon decreasing by increasing the velocity on the time - distance graph. In practice the time - distance graph for each layer is not completely obey the linear law, since the velocity is increased with depth in the same layer and strongly changed at the boundary of two layers (White, 1989; Berryman, 1991; Zelt, 1999). Based on these properties the separation of environment into different layers followed the time - distance curve can be realized not so difficult. The same properties can be applied to separate the velocity structural model into different layers. In this case instead of the slope change along the time-distance curve the difference in velocity gradient of different layer represented by the density of velocity isolines of the 
model is used. The infringement of linear law of the time - distance graph can happen when the interface between two layers is inclined or represented by the strong uplifted and subsidence, etc... The above-mentioned indications need to be taken into account during the process of data processing and interpretation. According to practical experience, a sudden velocity change along horizontal direction, the strong offset along vertical axis as well as the existence of narrow vertical block penetrated deeply into environment are the indications for identifying the tectonic faults and tectonic fracture zones. These objects also can be defined on seismogram by the strong offset of the same phase of waves along the time axis, or the change to hyperbolic shape of the time distance graph caused by wave diffraction.

Related to the petrology, the stratigraphic of the study area is characterized successively from the surface to the depth by Quaternary or weathered soil, the Paleozoic formations: Long Dai, Dai Giang and Tan Lam with composition of mainly claystone, sandstone, siltstone, limestone and dolomite. Though there aren't physical properties of the rock samples obtained from laboratory analysis, the consolidation degree is increasing with age was revealed by the investigations at a number of outcrops. Therefore, the environment in the study area is expected to generate refraction waves.

Based on the above - mentioned analysis and the purpose of this study, in the framework of the National Scientific Project (Code KC.08.16/11-15), 4 seismic profiles were conducted in the area of hot water spring Bang - Le Thuy - Quang Binh (Figure 1). This paper provides the information about structures in the area Bang based on the preliminary results of the refraction data analysis.

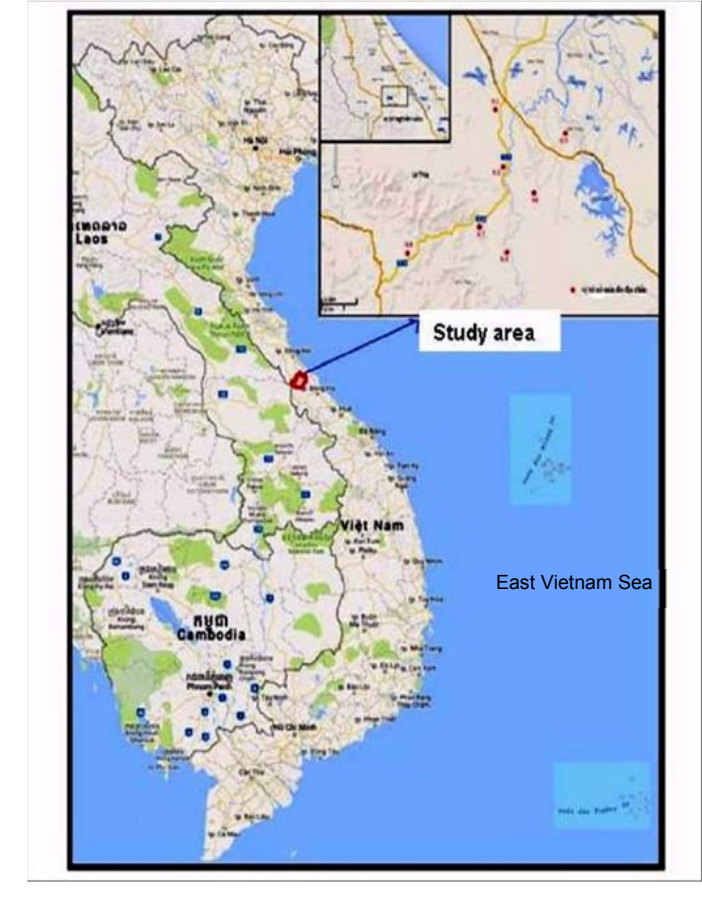

Figure 1. Location of the study area on the map of Vietnam

\section{Tectonic setting}

The hot water spring Bang is located in the southern margin of Quang Binh geotectonic unit. On the regional scale, the study area belongs to the eastern part of a large Truong Son uplifted structure, its geotectonic evolution is dominantly driven by the activity of the Khe Giua - Vinh Linh fault. According to the geological map of scale 1:1.000.000 (Tran Van Tri et al., 2004), this northwest southeast trending fault is stretching from Nakay plateau (Lao territory), entering into Vietnam at the south of the mountain Co Ta Run; the fault section in the territory of Vietnam is estimated $120 \mathrm{~km}$ long with the first segment paralleled with the upper stream of Long Dai River; the next segments are passed successively Khe Giua, Khe Bang (Le Thuy), North of Ben Quang, South of Ho Xa (Vinh Linh) and reaches the coastal line at Cua Tung. Cutting the study area and 
Tran Anh Vu, et al./Vietnam Journal of Earth Sciences 38 (2016)

experienced a long evolution history, the activity of this regional fault is profoundly affected to the neotectonic structural feature of the region. In the study area, about $15 \mathrm{~km}$ surrounding the hot water spring Bang, the fault segment named F1 is stretching nearly along the sub parallel direction and separates the study area into two main structural blocks: Le Thuy in the northern and Vinh Linh in the southern parts, respectively (Figure 2).

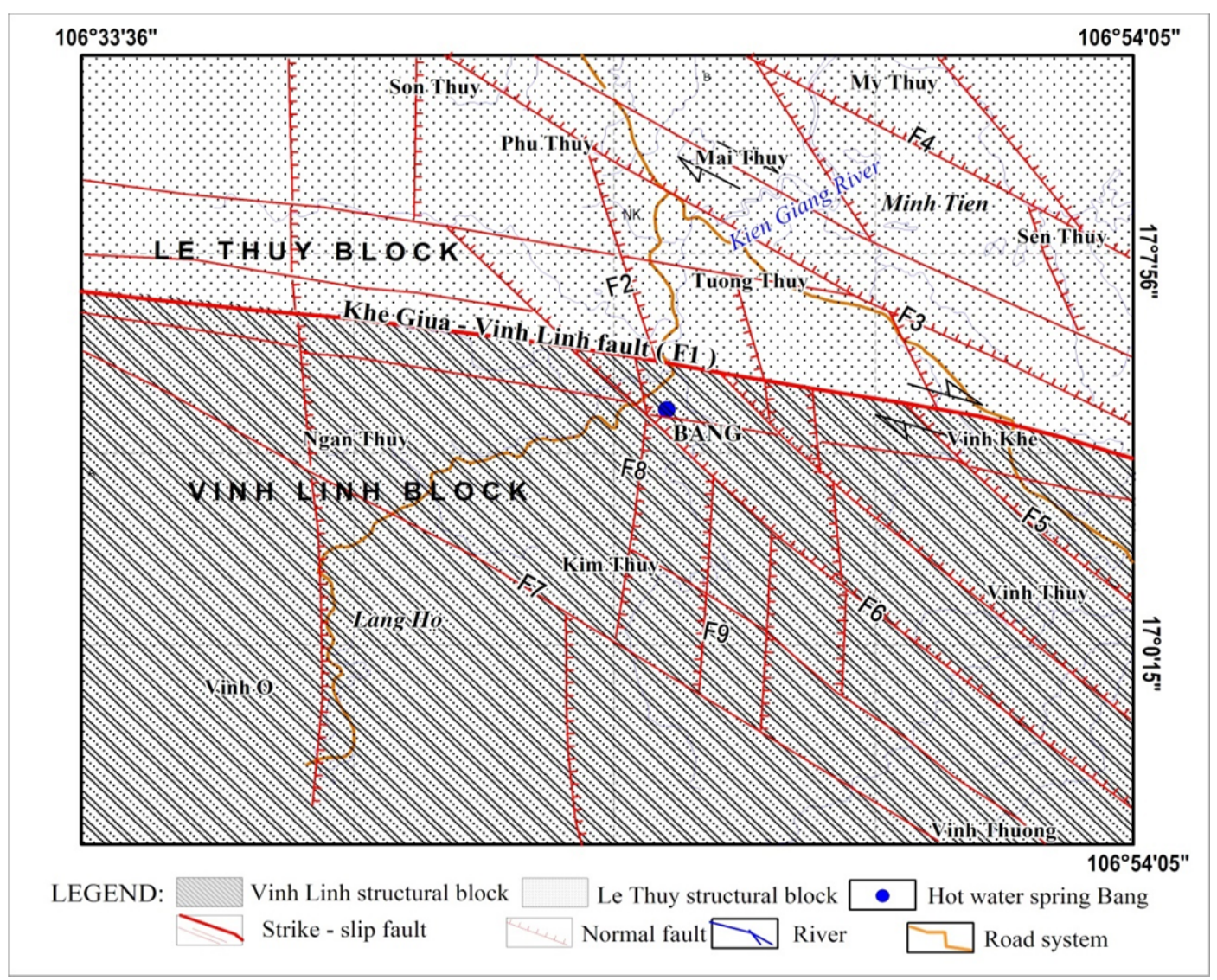

Figure 2. Geotectonic scheme of the study area

The Le Thuy block occupies the area belonging to three villages: Son Thuy, Truong Thuy and Van Thuy. The structure is developed on the basement of Truong Son folded uplifted belt, which was consolidated in the Paleozoic time and consists of continental, continental carbonate materials belonging to the Long Dai, Dai Giang and Tan Lam formations. The strong differentiation of movement during Cenozoic time had created a number of higher order structures, their boundaries are mainly the northwest - southeast trending faults. The subsidence rate is increasing from southwest to northeast, meanwhile the age of basement rocks is decreased from Early-Midle Paleozoic at the vicinity of Khe Giua - Vinh Linh fault to Middle Paleozoic age in the northeastern part of the block. The Quaternary sediment is also spread more popularly and thicker in this part. It is noted that, the basalt extrusion outcrop of Late Pliocene - Early Pleistocene age is distributed along the northwest - southeast direction fault and 
located away from the hot water spring Bang more than $5 \mathrm{~km}$ to the Northeast.

The Vinh Linh block occupies the southern part of the study area in the territory of Vinh O, Vinh Ha, Ngan Thuy and Vinh Khe villages. This structure is developed on the fold basement consolidated in Paleozoi and consists of continental, continental carbonate materials of the Long Dai and Tan Lam formations. In relation with the northern structural unit, the southern structure can be fairly accepted in term of the uplifted block. The strong differentiation of movement during Cenozoic time had separate the block into the high order structures, the boundaries of which are mainly the faults of northwest southeast direction. Though the age of the basement rocks is the same Early - Middle Paleozoic, younger tendency is demonstrated from southwest to northeast. In addition, in this block the density of sub meridian faults is higher than in the northern one, especially in the south of the hot water spring Bang.

Despite of the complexity of structural feature in the study area, the step subsidence tendency is apparently reflected in general from southwest to northeast and the most strong subsidence is revealed along Khe Giua - Vinh Linh fault (F1), which is the boundary between two main blocks. In relation to the faults, the northwest - southeast trending system is the most popular system spread in the study area. The younger sub meridian faults possibly related to the present day geothermal activity, including the hot water spring Bang, which was formed as the consequence of the Quaternary extension movement in the region.

\section{Field measurements and data interpretation techniques}

\subsection{Field measurements}

The seismic investigations aimed to provide the information about deep structure in the area of hot water spring Bang and surroundings for improving confidence of the study of geothermal system structures and the prediction of geothermal reservoir existence based on the magneto-telluric data. As mentioned above, the seismic refraction investigations were selected. According to the previous studies (Flynn, Hoang Huu Quy, 1997; Hoang Huu Quy, 1998; Doan Van Tuyen, 2016), the hot water spring Bang is generated by the activity of the northwest southeast trending fault system, including the F1, F6 and the smaller size sub meridian faults. It will be better if the measurement profiles are designed to cut as much faults as possible and their prolongation needs to reach the maximum value to increase investigated depth. Based on geological survey data (Tran Van Tri et al., 2004), the maximum thickness of all Paleozoic sediments may reach $3500 \mathrm{~m}$ in the region. If it will be the desire depth to investigate, the measurement profiles must be prolonged from about 4 times greater than that (Reynolds, 2011). Since the total thickness of Paleozoic sediments was roughly estimated by the geological survey data, the results are bearing mainly the regional significance and this parameter is still not clear for the study area. In addition, it is not certain to define the total thickness of all the Paleozoic sediments in this study. The strong topographical separation, the scattered distribution of population points and undeveloped transportation system do not allowed us to design the profiles of desire length. The wireless instruments used for data collection will be easier to realize with the local condition. Among 4 measured profiles, the longest profile $\mathrm{T} 1$ is $11.3 \mathrm{~km}$, profile $\mathrm{T} 2$ is 10.4 $\mathrm{km}$, the remain profiles $\mathrm{T} 3$ and $\mathrm{T} 4$ are only 8.05 and $7.65 \mathrm{~km}$ long, respectively (Fig. 3). 


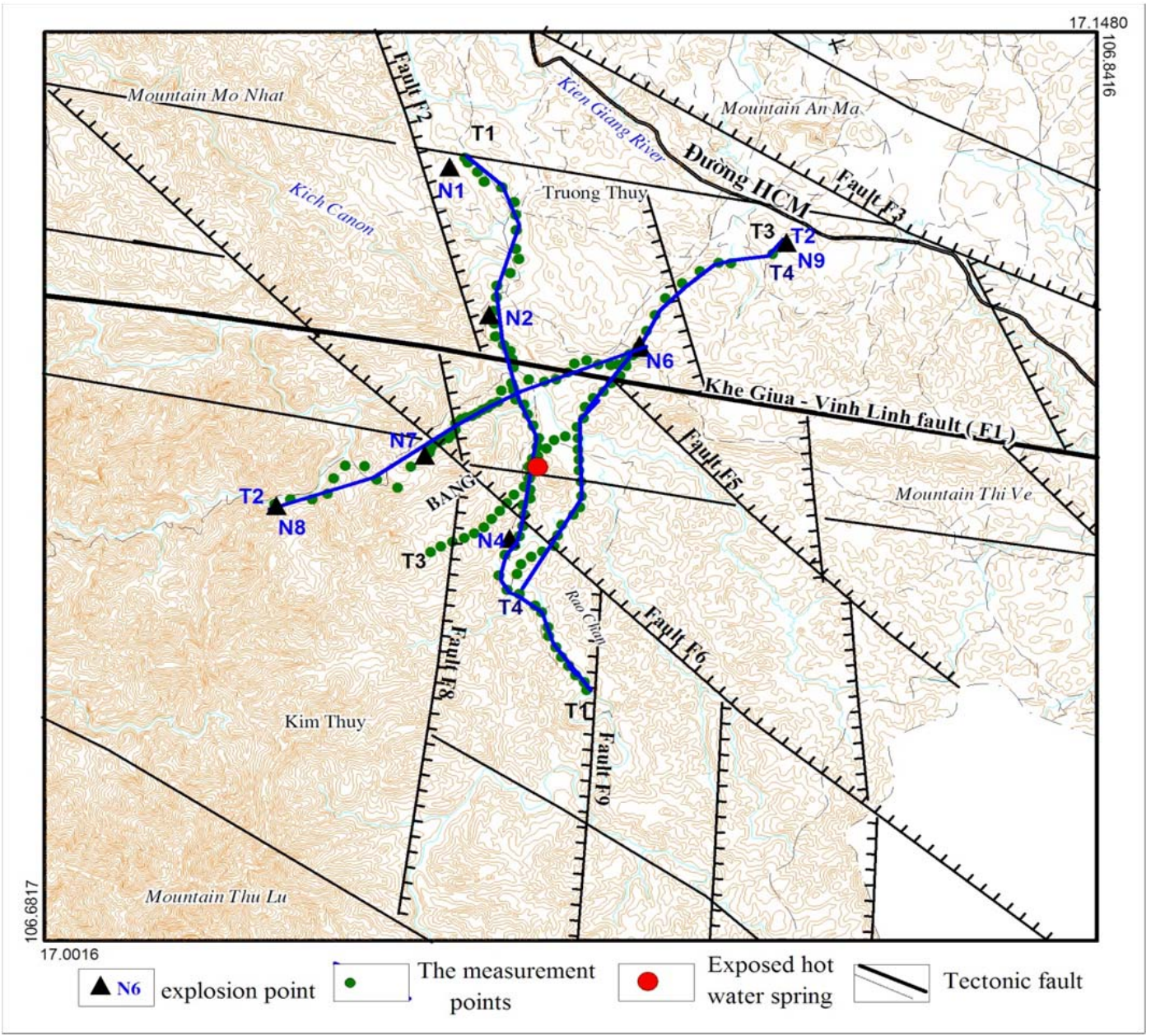

Figure 3. Scheme of the seismic investigation profiles in the area Bang and its

It is not necessary to use much dense instruments along each profile due to the study is not required to understand much detail of the subsurface layer, therefore the distances between the instruments selected in a range of $120-250 \mathrm{~m}$ are appropriated to the practical condition. 150 wireless Texan seismic instruments developed by the Refraction Technology Company, USA, the same type of instruments used in the study of deep structures in North Vietnam in 2008 (Dinh Van Toan et al, 2008, 2010; Harder, Dinh Van Toan, 2011) and provided by the Institute of Earth Sciences, Academia Sinica,
Taiwan were used in this study. Along the North-South direction profile T1 were deployed 52 instruments, 3 explosions at points N1, N2, N4 with the explosive mass of 100,60 and $60 \mathrm{kgs}$ respectively were realized to generate refraction signals. To produce refraction wave for 50 instruments distributed along the profile $\mathrm{T} 2,4$ explosions with the explosive mass 100, 40, 60, $100 \mathrm{kgs}$ respectively at 4 points $\mathrm{N} 8, \mathrm{~N} 7, \mathrm{~N} 6$ and $\mathrm{N} 9$ were conducted. The data collection along the profiles T3 and T4 with 36 and 34 instruments respectively was carried out by using 3 common explosions at the points N9, N6 and 
Vietnam Journal of Earth Sciences, 38(4), 393-408

N4 (fig. 3). The field work was successfully performed in March 2014, the GPS time synchronization was applied for every instrument just before their deployment. All the explosions were conducted in the drilling holes with the depths varied from 24 to $32 \mathrm{~m}$. Since the farthest source - receiver distance along each profile is equal to their lengths, so explosive mass of $100 \mathrm{kgs}$ were chosen for the explosions at the end points of the profiles and 40-60 kgs for the explosions at their internal points. The safety guarantee for the civil structures and population points as well as the strong enough signals of refraction wave generation from every explosion are the requirements must be satisfied at the same time.

According to the experiments (Ester, 2010; Tesarik, 2011) and experience (Uruh et al., 2001; Dinh Van Toan, Harder, 2008; Dinh Van Toan et al., 2011; Harder, Dinh Van Toan, 2011), the chosen plan for explosion in boreholes as mentioned above is satisfied both demands. The data recorded in the format of instruments then were transformed into other format such as Miniseed, Segy for easy reading by different software used in seismic analysis. By reading all the seismograms on the computer screen we can see a good quality of the collected data, the first arrival signal of refraction wave clearly appears on the records of every instrument. The seismogram recorded by the instrument No. 14239 on March 14, 2014 produced by the explosion at point N1, profile T1 (fig. 4) is a good example. The first arrival signal on the record is reflected by the sudden increase of wave amplitude at the time moment 05:28:73.0. Thus the arrival time can be precisely picked by the software named Seismogram $2 \mathrm{~K}$ during the data analysis process. On the seismic section constructed by the data recorded by all the instruments along the profile T1 (fig. 5), the connection of all the first arrival times marked by the strong increase of signal amplitude creates the time - distance graph of refraction wave with different slope to the abscissa from segment to segment. By intuition it is not so clear to see the separation into different straight segment due to a small scale of the seismic section, however 3 distinguished near straight segments of the different slope to the horizon corresponded to different refraction interface with different velocity in the environment were identified. In this study the seismograms recorded by individual instrument is used for picking the first arrival time, since the signal on it is much more clear than on the seismogram created by combination of the data records of all instruments.

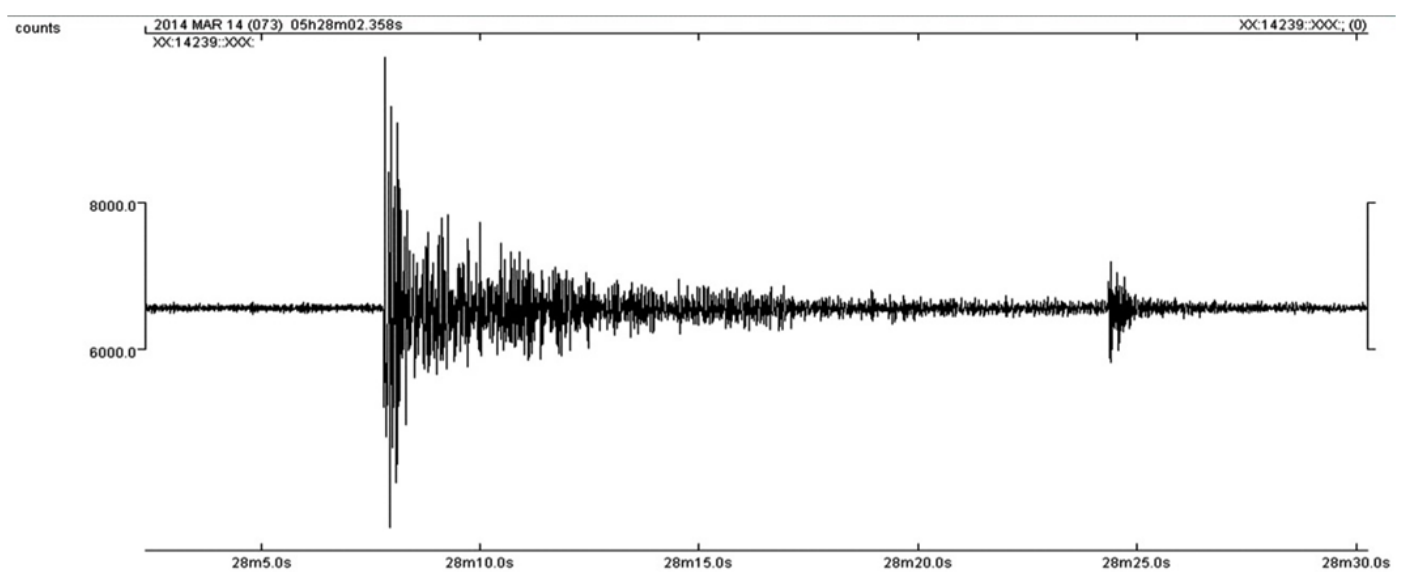

Figure 4. Quality of the seismic signals recorded by individual instrument 
Tran Anh Vu, et al./Vietnam Journal of Earth Sciences 38 (2016)

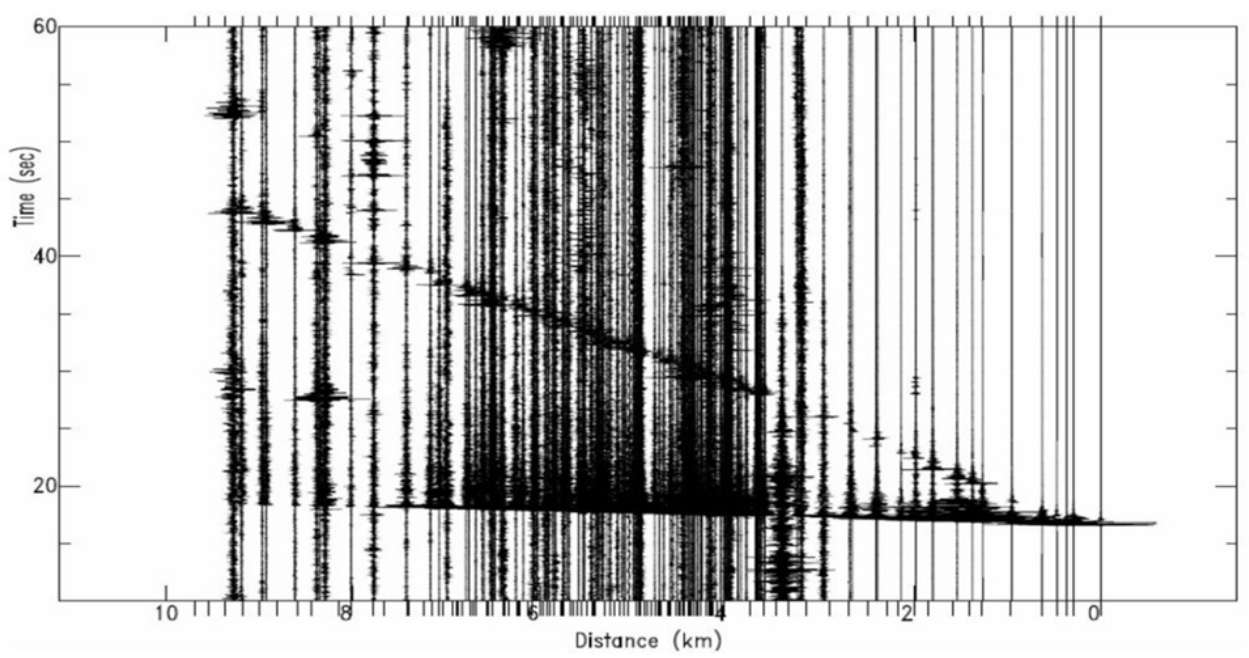

Figure 5. Seismogram created by the records of all the instruments along profile T1 with the explosion at the point N1

\subsection{Method of data analysis}

Construction of seismic velocity model under observation profile is the purpose of data analysis. The 2D seismic inversion will be applied and tomographic technique is used to construct the velocity model under the investigation profiles.

\subsubsection{The algorithm and software used for data analysis}

Our problem is seeking the velocity structural model under the observation profiles, so that the difference of theoretical travel time in comparison with the observation is need to be small enough. This paper just deals with the first arrival refraction wave appeared on the seismograms and generated by underground layered environment. The first step of inversion is to solve the forward problem, i.e. the initial structural model must be constructed by an interpreter and than the wave travel times from sources to receivers will be calculated. The comparison between the theoretical calculated travel time curve and the observation data is the next step. If the difference between them is not small enough, the parameters of the model, included the depths to different interfaces as well as the velocity in each layer will be changed by using the least square techniques for minimizing the target function. The iterative process of calculation is continued until the difference between the theoretical and observation travel time curves became small enough and the parameters, including the velocity and the distribution of different layers in the last calculation are accepted as the structural model consistent to the real environment (White 1989; Berryman, 1990; Pullammanappallil et al., 1994; Udias, 1999; Zelt, 1999). At present the ray tracing theory is popularly used for calculation of the theoretical travel times. In this study the seismic tomography is realized by using the software named Plotrefa, the product of Geophysical Instrumental Company OYO 2003. According to the algorithm, the velocity distributions under observation profile are discretely represented in the nodes of grid by the values increased with increasing depth (fig. 6). In this case the calculation of source receiver travel times follows the formula:

$$
\mathrm{T}_{\mathrm{j}}=\sum_{\mathrm{i}=1}^{\mathrm{i}=\mathrm{N}} \mathrm{S}_{\mathrm{i}} \mathrm{L}_{\mathrm{ji}} \quad \mathrm{j}=1,2, \ldots, \mathrm{M}
$$

Here $\mathrm{M}$ - the number of instruments; $\mathrm{N}$ the number of segments along the wave ray passed the environment and separated by the grid network. 


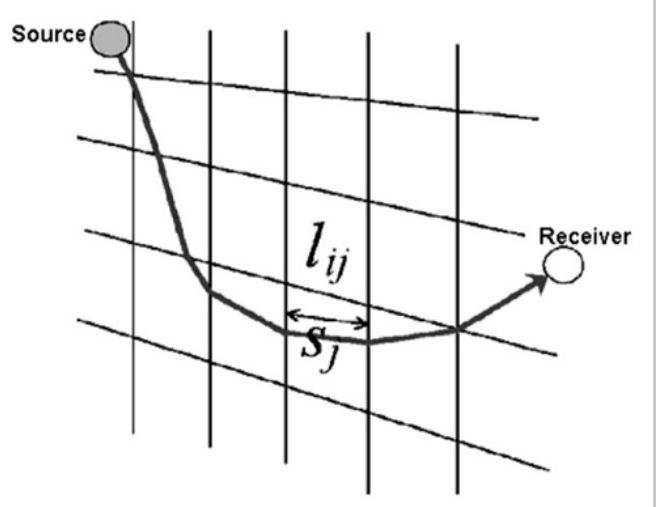

Figure 6. The seismic ray from source to receiver in the investigated environment

To calculate the theoretical travel time curve both the initial layered structural model as well as minimum and maximum velocity values corresponded to the subsurface and deepest layers must be given by an interpreter; the number of layers can be also changed during the iterative calculation process. In this study the increasing velocity with depth obeyed the exponential law will be calculated and it's values at each node of the grid is automatically accepted during the calculations. As mentioned above, if the difference between the theoretical and observation travel time curves $\mathrm{T}_{\text {ilt }}$ and $\mathrm{T}_{\mathrm{iqs}}$ is still not small enough, the iterative calculation is continued on the basic of least square techniques to change the model parameters:

$$
E=\frac{1}{M} \sum_{i=1}^{i=M}\left[T_{i l t}-T_{i q s}\right]^{2}=\text { Min }
$$

Since the function $\mathrm{E}$ can reach a minimum when $\partial \mathrm{E} / \partial \mathrm{m}_{\mathrm{j}}=0$, therefore the parameters need to be changed in the next iteration are calculated from formula:

$$
\mathrm{T}_{\mathrm{j}}^{\mathrm{k}+1}=\mathrm{T}_{\mathrm{j}}^{\mathrm{k}}+\partial \mathrm{E} / \partial \mathrm{m}_{\mathrm{j}}
$$

Here $\partial \mathrm{E} / \partial \mathrm{m}_{\mathrm{j}}$ - partial derivative of the parameter $\mathrm{m}_{\mathrm{j}}$, possibly the velocity or the depths in the nodes of grid; $\mathrm{k}$ - the numerical order of iteration.
Thus, to prepare the input data for modeling, the definition of the source receiver observation travel times for all the instruments along the profiles is needed to be performed firstly. Since the instruments used in this study are wireless, so the travel times are determined by subtraction of the travel time at the instrument located in 2 to $4 \mathrm{~m}$ around a shot point from the travel times at the instruments distributed along the profiles. The refraction signals are clearly reflected from the collected data, especially when the seismograms were read by using the program Seismogram $2 \mathrm{~K}$ developed by the Antony Lomax company, USA. The frequency, amplitude filtering and zoom functions can be operated by this program. Though the first arrival wave is indicated stronger than the noise on all the recorded seismograms, the band pass filtering operation was applied to increase the resolution in time for the signals. In consequences the pick of first arrival times is became more easy and more reliable (fig. 7). All the travel times related to each explosion along each profile were used for construction of the time - distance graphs. Due to the analysis program works just with the equidistance distribution data, the first time - distance graph created from really unique distance collected data were transformed into the equidistance graph by using the linear interpolation technique. The chosen window comprises just 2-3 points of data, so their connected line is not much declined from the linear law as the reason of the small error of the interpolation in this study (fig 8). An inconsiderable difference both in values and shape of the time - distance curve constructed from the real and interpolation data is reflected in this figure. The largest error for the profile $\mathrm{T} 1$ reached $27.9 \mathrm{~ms}$ (millisecond) is generated by the interpolation of the time - distance curve obtained from the explosion at the point N4; the value $20.55 \mathrm{~ms}$ is the largest error corresponded to the explosion at the point N9 for profile T2 and the values of 11.8 and $29.24 \mathrm{~ms}$ are the largest interpolation errors related to the common explosion at the point N9 for the profiles $\mathrm{T} 3$ and $\mathrm{T} 4$, respectively. 
Tran Anh Vu, et al./Vietnam Journal of Earth Sciences 38 (2016)
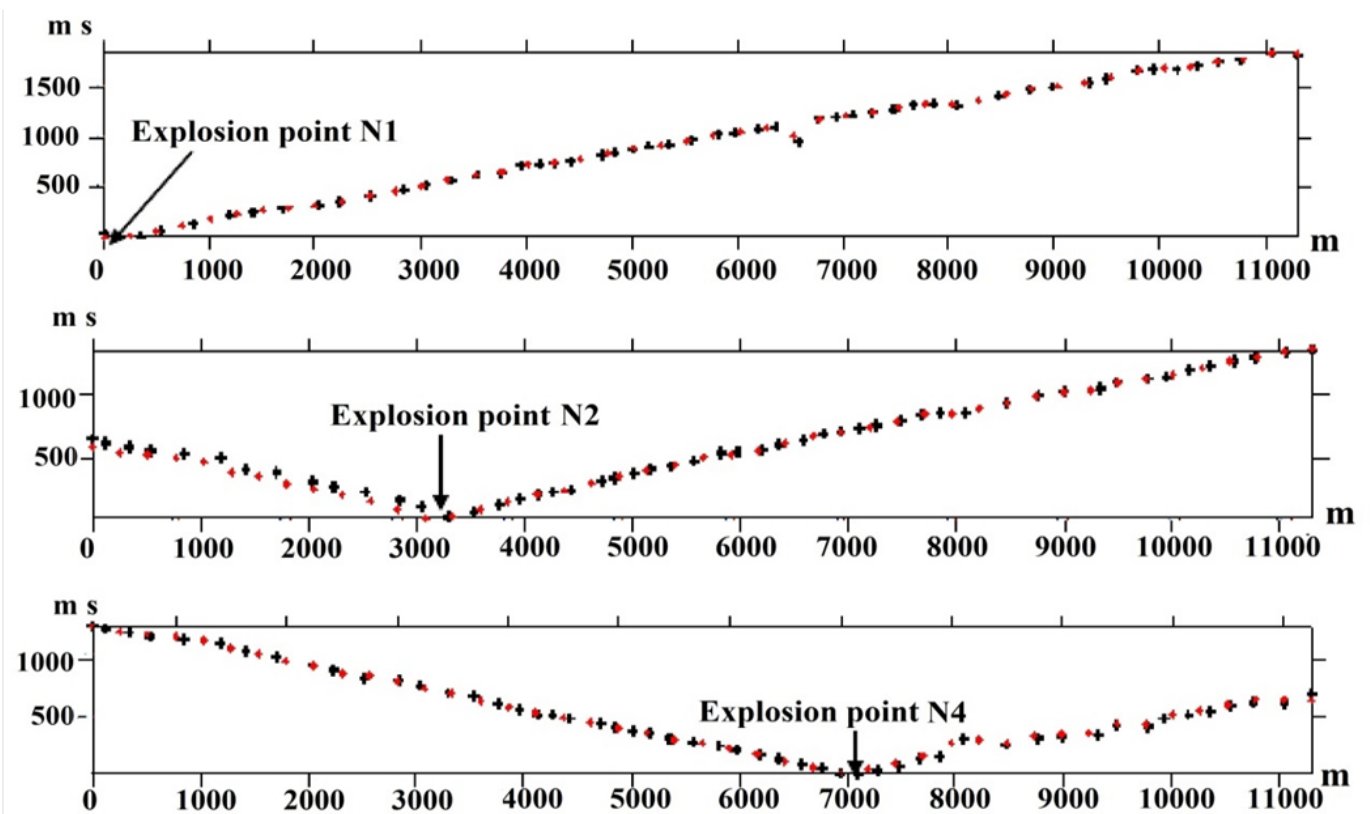

$+\quad$ The observed Source - Receiver travel times for 3 explosions along profile T1

- The travel times interpolated from the observed for the equal distance network

Figure 7. Picking the first arrival time on the seismogram recorded by individual instrument

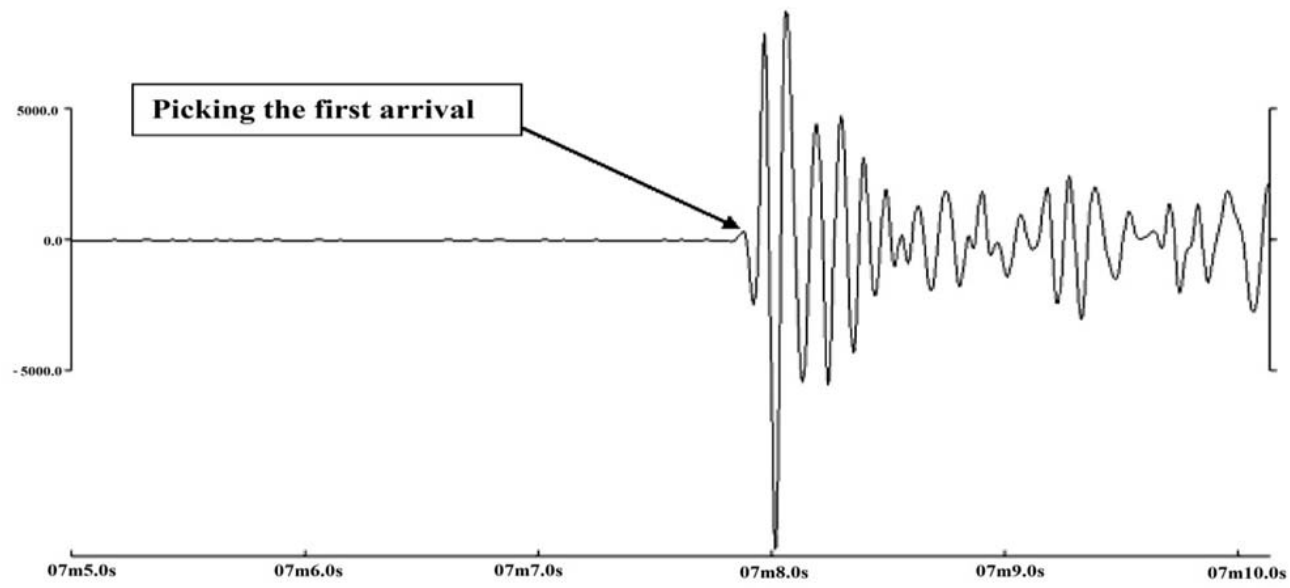

Figure 8. The equal distance time - distance graph obtained by the interpolation of the observation data

\subsubsection{The seismic modeling}

After entering the travel time data into the program Plotrefa the time - distance graph is

generated. The modeling is carried out in two stages. A simple three layered model is constructed in the first stage with the velocity determination for each layer based on the 
slope of near straight segments on the time distance graph. If the environment is reflected by more than three layers on the graph, the couplement of several near straight segments with a small difference in their slope is applied to generate a common segment. In such a way we can roughly estimate the velocity change with depths, including the smallest and greatest values referred to the velocity of subsurface and an average velocity of the deepest layers of the environment. The derived parameters are now accepted as the input data for modeling by using the seismic tomographic technique in the second stage. In this case, an arbitrary multilayered model can be applied to generate the initial model with the minimum, maximum velocities and the values of the depth to the deepest interface accepted from the first stage. Now the modelling can be solved by the finite-element algorithm in combination with the least square technique. In this study, multi-time iterative calculation was carried out with the number of layers changed within a range 15 - 30 layers; the parameters such as the smallest and greatest velocities were also changed in different iterative calculations. Since the algorithm accepted a constant velocity for each layer, so increase of a number of layers allows creating a model, better consistent with the real environment. However, an increase of a number of layers is involved the increase of the parameters participated in the minimizing process. It may become the reason for the algorithm to work unstably. In brief, to find the model characterized by a small deviation between the theoretical and observation travel times as well as better consistent with the real environment, the alteration of a number of layers and the velocities is needed. With the above-mentioned purpose, the calculations were performed by the combination of the automatic minimization and the computer interpreter conversation during the analysis.
The experiences showed that, the iterative calculations can be terminated when the deviation between the theoretical and observation travel times is small enough, or it approaches a mostly constant value in the next several iterations. Using the results from the calculations in this study, the velocity structural models under 4 profiles were constructed. The tectonic characteristics of the study area are reflected in these models. An average square error generated during the calculations is ranged from 11.2 to $21.2 \mathrm{~ms}$. Since the longest source - receiver travel times along the profiles ranges from 1500 to $1851 \mathrm{~ms}$, the error derived from the calculations in this study is small enough and can be accepted.

\section{Results and discussion}

The velocity structural model along the profile $\mathrm{T} 1$

Along the north - south direction, the profile T1 started from the northern flank of the sub parallel fault distributed more than $4 \mathrm{~km}$ to the north of the Khe Giua - Vinh Linh fault (F1), then passed the hot water spring Bang and continued to the south more than $5 \mathrm{~km}$. The largest source - receiver travel time recorded by the instrument at the south end point of the profile reached $1851 \mathrm{~ms}$ with the explosion at northern end. The deviation between the theoretical and observation travel times in term of an average square error corresponded to the resulted model is $19.5 \mathrm{~ms}$ (fig. 9a). According to the velocity distributions (fig. 9b), a large subsidence structure occupied the section mostly from northern end to the position $>7000 \mathrm{~m}$ along the profile is detected. The remain southern section of the profile is an uplifted block with the basement consist of hard rocks which reflected by the high value of velocity of about $6.4 \mathrm{~km} / \mathrm{s}$. Based on the velocity distribution in the seismic section, the structural model can be divided into layers as follows: 
Tran Anh Vu, et al./Vietnam Journal of Earth Sciences 38 (2016)

The first or subsurface layer is characterized by very rapidly increase of the velocity with increasing depth in the subsidence block. In a thin layer with the thickness estimated of $200 \mathrm{~m}$ at the northern, $60-70 \mathrm{~m}$ at the middle and approximately
$400 \mathrm{~m}$ at the southern segments of the profile the velocity varies from $3.0-4.1 \mathrm{~km} / \mathrm{s}$. The above-mentioned velocity range is probably related to the well weathered product in the shallower depth and not completely weathered soil in the deeper section.

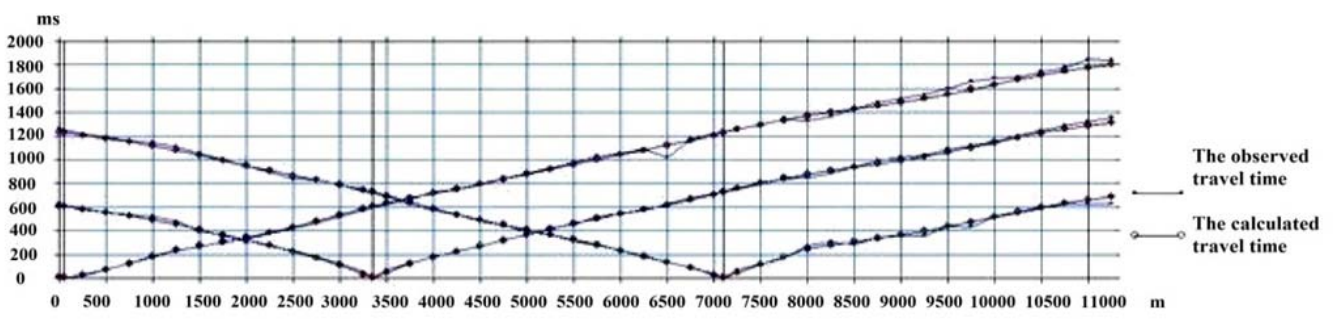

Figure 9A. Deviation between the theoretical and observation time - distance curves of profile T1

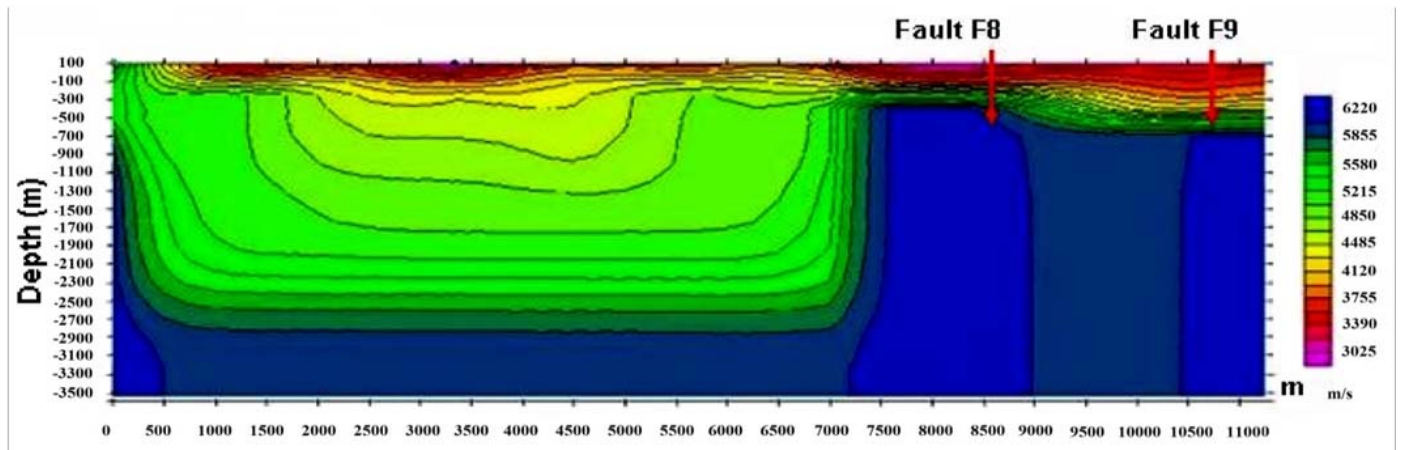

Figure 9B. Seismic velocity structural model under profile T1

Much slowly increase of the velocity with depth is the indication of the separation of the second layer from the others. It's values vary from $4.1 \mathrm{~km} / \mathrm{s}$ to $5.1-5.2 \mathrm{~km} / \mathrm{s}$ in a layer with thickness of up to $1600 \mathrm{~m}$ (from the depths of $200 \mathrm{~m}$ to $1800 \mathrm{~m}$ ) in the subsidence block. The layer became much thinner with $200-300 \mathrm{~m}$ in thickness in the uplifted block at the remained southern section. Thus the basement of the uplift is revealed at shallow depths from $500 \mathrm{~m}$ to $650 \mathrm{~m}$. According to the recent magnetotelluric data, at the horizon of $1500-1600 \mathrm{~m}$ deep in the subsidence block is revealed the boundary which separates the overlying high resistivity from the underlying low resistivity layers (Doan Van Tuyen et al., 2015; 2016).

The higher velocity gradient in comparison with the second layer is demonstrated again in the third layer. With less than $1 \mathrm{~km}$ in thickness, inside the subsidence structure, the layer is characterized by the velocity about 5.2 $\mathrm{km} / \mathrm{s}$ at the depth of $1800 \mathrm{~m}$ and increased up to $6.0 \mathrm{~km} / \mathrm{s}$ at the depth $2700 \mathrm{~m}$ along the bottom of the layer. In the uplifted block along the southern segment, the thickness of the layer is strongly decreased to $200-300 \mathrm{~m}$.

The deepest layer that can be seen in the seismic section is reflected by the velocity range of $6.0-6.2 \mathrm{~km} / \mathrm{s}$ in the area of subsidence block. However a more complicated feature is indicated by the velocity distribution in the basement of the southern uplifted structural block. Here, inside the well consolidated rocks in the basement which reflected by the velocity of more than $6.4 \mathrm{~km} / \mathrm{s}$, a narrow vertical 
structure with $1.3 \mathrm{~km}$ wide appeared and represented by lower velocity of $6.0-6.2$ $\mathrm{km} / \mathrm{s}$. This phenomenon may be related to the fracture zone developed inside the basement and possibly contained some water content. The area with the low velocity structure is located in the south of the northwest - southeast trending fault F6 as well as between two sub meridian faults F8 and F9. According to the experiences from the studies of geothermal sources (Honjas et. Al., 1997; Uruh, 2001) and the results of recent magneto-telluric investigations (Doan Van Tuyen et al., 2015) the section occupied by the lower velocity structure is directly above the geothermal reservoir predicted from the depth $>2 \mathrm{~km}$. From the correlation between the seismic and tectonic data we can see the clearest vertical boundary detected by the seismic data is the F6 fault. It also plays a role of a boundary which separates the southern strong uplifted from the northern subsidence blocks along the profile T1. The strong subsidence cliff revealed by the seismic data in the near northern end of the profile indicates an unnamed fault located to the North and paralleled the Khe Giua - Vinh Linh fault F1. It is noted that, in the seismic section the fault $F 1$ is reflected by the subsidence wall developed just in the shallow layers from surface to the depth of $1.3 \mathrm{~km}$ at the position $4500-5000 \mathrm{~m}$ along the profile, meanwhile the auxiliary fault also paralleled the F1 but located in it's south is revealed in the only deeper section at the position $>4600 \mathrm{~m}$ along the profile $\mathrm{T} 1$.

The velocity structural model along the profile $\mathrm{T} 2$

The southwest - northeast direction profile $\mathrm{T} 2$ is cutting the profile $\mathrm{T} 1$ at the point 5400 $\mathrm{m}$ accounted from its southwest end, then passing the location distributed to the North of the Bang spring about $1500 \mathrm{~m}$. The velocity in the seismic section varies from less than 3.0 $\mathrm{km} / \mathrm{s}$ to $6.4 \mathrm{~km} / \mathrm{s}$ (fig. 10). According to the velocity structures, in the section stretching from the southwest end to the position 3500 $4000 \mathrm{~m}$ along the profile T2 a strong uplifted block which consists of well consolidated rocks in the basement and clearly reflected by the high velocity is revealed. Closed to the southwest end of the profile the hard rock estimated by the velocity $6.4 \mathrm{~km} / \mathrm{s}$ is distributed at the depth of approximately $500 \mathrm{~m}$. The uplift tendency continues up to $200 \mathrm{~m}$ depth in the next segment and terminated by the tectonic fault F6. From this point to the position $7000 \mathrm{~m}$ along the profile the subsidence structure is detected by the refraction boundary distributed at the depth of $2.1 \mathrm{~km}$ with the velocity reaching $6.0 \mathrm{~km} / \mathrm{s}$. The stronger subsidence revealed at the last northeast segment of the profile with the refraction interface distributed at the depth of $2 \mathrm{~km}$, which is reflected by the low velocity values of $5.1-5.2 \mathrm{~km} / \mathrm{s}$. Here the boundary of velocity higher than $6.0 \mathrm{~km} / \mathrm{s}$ is revealed in the central section, then sank deeper and can not be detected by the seismic investigations in this study. The transition zone characterized by the change of velocity from $5.6-5.7 \mathrm{~km} / \mathrm{s}$ to lower than $5.3-5.4 \mathrm{~km} / \mathrm{s}$, detected at the position $7000-7500 \mathrm{~m}$ along the profile, is the place occupied by the Khe Giua - Vinh Linh fault (F1). Based on the velocity distributions under profile $\mathrm{T} 2$, the structures can be divided into three main blocks with relatively strong subsidence tendency from southwest to northeast. The thickness of every layer is also increased along this direction, meanwhile the consolidation degree of the rocks is inversely decreased. The similar features are demonstrated by the velocity structures in the seismic sections of profiles T3 and T4. The direction of these profiles is mostly the same with profile $\mathrm{T} 2$, but their shorter length is the reason to limit the investigation depth. The velocity range appeared in the seismic sections under the profiles $\mathrm{T} 3$ and $\mathrm{T} 4$ is 
Tran Anh Vu, et al./Vietnam Journal of Earth Sciences 38 (2016)

mostly corresponding with the two upper layers under the other profiles and the third layer can not be reached by the seismic investigations along these profiles.

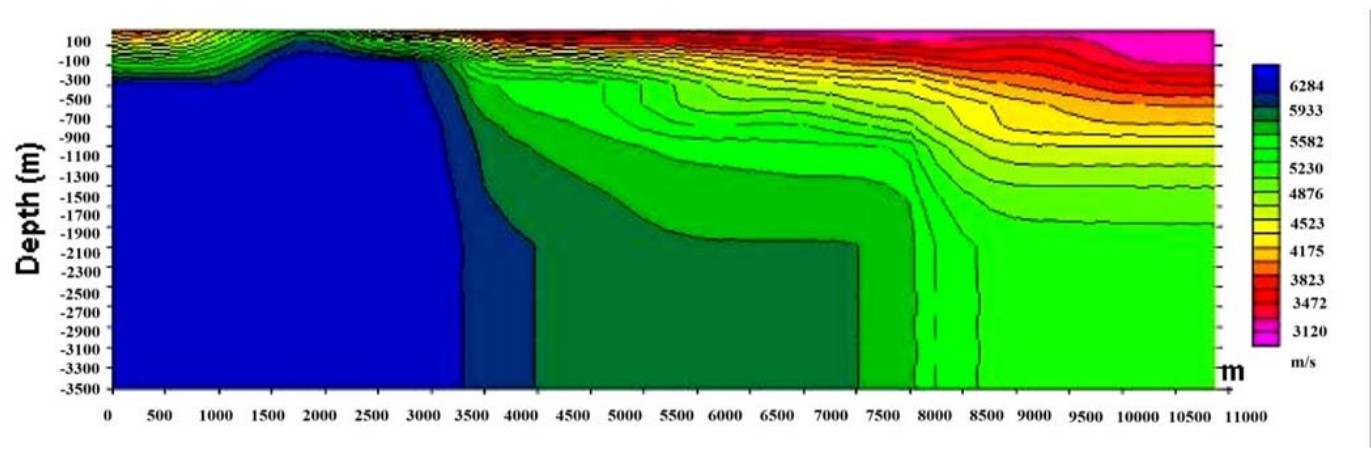

Figure 10. Seismic velocity structural model under profile T2

\section{Conclusions}

A good quality seismic data was recorded by all the deployed instruments in the area of the hot water spring Bang - Quang Binh. The limitation in length of the measurement profiles caused by the complexity of the local condition is restricted the investigation depth in a range of $2-3 \mathrm{~km}$.

The velocity structural models under 4 profiles constructed by the results of data analysis are consistent with the structural feature of the study area. According to these models, the strong uplifted block constituted from hard rocks in their basement is spread from the fault F6 southwestward. The relatively subsidence structure is revealed in the area located between the faults F6 and Khe giua - Vinh Linh (F1); The subsidence tendency continues to the northeast creating the most subsidence block in the northeastern part of the study area.

At the southwestern margin of the fault F6 or the south of the hot water spring Bang in more than $2 \mathrm{~km}$, a narrow lower velocity structure is found inside the hard rock block with $1.3 \mathrm{~km}$ wide. Its properties reasonably referred to the fracture zone and may be related to the geothermal fluid conducted in the past geological time. The extension activity in the Quaternary time is indicated by the restriction of the block bounded by two sub-meridian faults in this area. This sign fortifies confidence about the existence of the geothermal reservoir from depth $>2 \mathrm{~km}$ predicted by the recent magneto-telluric.

The results of seismic data analysis in this study can be accepted as a first product, since the software used for data analysis indicates some limitations, such as the program is just working with the data collected in an equidistance network of points. In addition, the use of non-straight lines of the investigation profiles is the reason to obtain the higher velocity in comparison with the real value. A more improvement of the data analysis can be done if the correction of the travel times will be applied to reduce the effect of the non-straight profiles as well as use of more appropriate software, including the program for $3 \mathrm{D}$ inversion.

\section{Acknowledgements}

This work is supported by the Vietnam National project (KC08.16/11-15). The authors would like to express the gratefulness for this support. We also sincerely thank Huang Bor-Shouh and his colleagues: Liu. Yang, Lin from the Institute of Earth Sciences, Academia Sinica, Taiwan for 
Vietnam Journal of Earth Sciences, 38(4), 393-408

providing the seismic instruments as well as their active participation in the field work during the investigations.

\section{References}

Berryman J. G., 1991, Lecture Notes on nonlinear inversion and tomography. Earth Resources Laboratory, Massachusetts Institute of Technology, USA, pp. 164.

Ester Z., Darko V., 2010, A careful blasting technique during construction of underground opening for nuclear waste repository. Pub. of University of Zagreb, Croatia, https://www.iaea.org.inis/collectionStore/public/29/0 64/29064418.pdf, 384-390.

Flynn T., Quy H. H., 1997. Assessment of the geothermal resources of Socialist Republic of Vietnam. Geothermal resources Council Transactions, vol.21, 341-345.

Hoang Huu Quy, 1998. Overview of the Geothermal potential of Vietnam. Geothermics, Vol.27, n.1, 109-115.

Honjas W., Pullammanappallil S. K., Lettis W. R., Plank G. L., Louie J. N., and Dchweichert R., 1997, Predicting subsurface structure within the Dixie Valley geothermal field, Dixie Valley, Nevada, using a non-linear optimization scheme: Geothermal Resource Council Bullentin, v. 26, p. 45-52.

Pullammanappallil S. K., and Louie J. N., 1994, Generalized simulated-annealing optimization for inversion of first arrival times. Bullentin of the seismological society of America, v.84, 1397-1409.

Harder Steven, Van Toan Dinh, 2011. Collecting Deep Seismic Data in Densely Populated Vietnam. EOS, Transaction; American Geophysical Union, Vol. 92, No 3, 21-22, 18/1/2011.

Thorne Lay, Terry C. Wallace, 1995. Modern global Seismology. Academic Press. Inc., San Diego, California $521 \mathrm{pp}$.

Mai Thanh Tan, 2011. Seismic Prospecting. Transportation publishing house, Hanoi, 524pages (in Vietnamese).

Tesarik D. R., W. A. Hustrulid, and U. Nyberg, 2010, Assessment and application of a single-charge blast test at the Kurina mine, Sweden, https:/www.cdc.gov.hiosh/minning/userfiles/works/ aaaoa.pdf.
Dinh van Toan, Steven Harder, Pham Nang Vu, Trinh Viet Bac, Doan Van Tuyen, Lai Hop Phong, Tran Anh Vu, Nguyen Thi Hong Quang, 2008. The first deep seismic investigations in North Vietnam. Vietnam J. of Geology, series B, N31-32, 213-219.

Dinh Van Toan, Steven Harder, 2008, Near-vertical Moho reflections under Hanoi Basin, Vietnam. EOS Trans. 89(53), AGU Fall meeting Supplement abstract S13D-03.

Dinh Van Toan (project manager), et al., 2010. Study on deep crustal structures of Northern Vietnam with the purpose to obtain a more confidence in the geological hazard prediction by using deep seismic and magneto-telluric investigations. Final report of National project (Code KC.08.16/11-15), 228 pages, Hanoi, Institute of Geological Sciences.

Dinh van Toan, Steven Harder, Trinh Viet Bac, Doan Van Tuyen, Lai Hop Phong, Tran Anh Vu, Nguyen Thi Hong Quang, 2011. Study on the Earth crustal structure by the seismic refraction data collected along two profiles in Northern Vietnam. Vietnam Journal of Earth Sciences, T33(3), 538 - 548.

Tran Van Tri (Project manager), et al., 2004. Map of geology and mineral resources of Vietnam on scale $1: 1,000,000$. Publication of the Department of Geology and mineral recources of Vietnam, Hanoi (in Vietnamese).

Doan Van Tuyen, Dinh Van Toan, Trinh Viet Bac, 2008. The study of geothermal resources to develop clean energy in Vietnam. Vietnam Journal of Earth Sciences, 30(2), 153-160.

Doan Van Tuyen, Tran Anh Vu, Lai Hop Phong, Le Van Si, Pham Ngoc Dat, Duong Thi Ninh, Dinh Van Toan, Nguyen Thi Hong Quang, 2015. Results of magneto-telluric survey for studying geothermal system in area Bang - Quang Binh province Vietnam Journal of Earth Sciences 37(1), 48-56.

Doan Van Tuyen, Tran Anh Vu, Lai Hop Phong, Dinh Van Toan, Le Van Si, 2015. Structural Features of Geothermal Field from Magneto-telluric Survey in Northern Central Region of Vietnam. Proceedings of World Geothermal Congress 2015, Melbourne, Australia, 1-25 April 2015, Onlinehttps://pangea.stanford.edu/ERE/db/WGC/2015.

Doan Van Tuyen ( project manager),et al. 2016. A study of the potential geothermal resources for energy development in Vietnam. National project (Code KC.08.16/11-15), final report, 228 pages, Hanoi, 
Tran Anh Vu, et al./Vietnam Journal of Earth Sciences 38 (2016)

Institute of Geological Sciences ( in Vietnamese). Reynods J. M., 2011, An introduction to applied and environmental geophysics. John Wiley \& Son, Ltd., Chichester, $2^{\text {nd }}$ ed., 712 pp.

Udias Agustin, 1999. Principles of Seismology. Cambridge University Press, 475 pp.

Uruh J. R., Pullammanappallil S. K., and Honjas W., 2001. New seismic imaging of the geothermal field, eastern California: Proceedings of the $26^{\text {th }}$ workshop on Geothermal Reservoir Engineering, Standford University, CA, January 29-30.

White D. J., 1989. Two dimensional seismic refraction tomography. Geophys. J. Int., 97, 223- 245.

Zelt Colin A., 1999. Modelling strategies and model assessment for wide-angle seismic traveltime data. Geophys. J. Int., 139, 183-204. 